\title{
Awareness on Intraligamentary Injection Among Dental Students- A Questionnaire Survey
}

\author{
A.Ashwatha Pratha ${ }^{1}$ and Dhanraj Ganapathy ${ }^{2}$ \\ ${ }^{1}$ Department of Prosthodontics, Saveetha Dental College and Hospitals, Saveetha Institute \\ of Medical and technical sciences(SIMATS), Saveetha University, Chennai, India. \\ ${ }^{2}$ Professor and Head, Department of Prosthodontics, Saveetha Dental College and Hospitals, Saveetha \\ Institute of Medical and technical sciences (SIMATS), Saveetha university, Chennai, India.
}

\section{ABSTRACT}

Intraligamentary injections are preferred primary technique when anesthesia of short duration is desired and a safer alternative when limited soft-tissue anesthesia for simple single-tooth extraction is required or for patients with bleeding tendencies.This survey aimed at assessing the knowledge and awareness of intraligamentary injection technique among dental students. The study was done in an online setting among the dental students of the Chennai population. The sample size of 150 participants of age group 20-23 years, both males and females were selected by a simple random sampling method. Both descriptive ( frequency of the responses) and inferential statistics (Chi - square tests) were done and the results were presented in the forms of graphs. According to this survey based study it was noted that the females(64\%) have participated in higher numbers compared to males(36\%). It was noted that 59.33\% of the population participated in the study were aware of the term PRP (ie. platelet rich plasma) whereas 40.67\% of the population was not aware of the term. Within the limitations of this study, it was inferred that the knowledge and awareness of platelet rich plasma was different among both the genders. More appropriately, females were much aware compared to males

KEY WORDS: ANAESTHESIA; AWARENESS; PAIN; PDL.

\section{INTRODUCTION}

Local anesthesia forms the major part of pain-control techniques in dentistry (Singh, 2012). Patients expect a painless and comfortable dental treatment, which becomes crucial especially in subjects suffering from dental phobia (Yamashiro and Furuya, 2006). The selection of a local anesthetic for intraoral injection must include considerations of efficacy, safety, and individual

\section{ARTICLE INFORMATION}

*Corresponding Author: dhanraj@saveetha.com

Received 17th June 2020 Accepted after revision 5th August 2020

Print ISSN: 0974-6455 Online ISSN: 2321-4007 CODEN: BBRCBA

Thomson Reuters ISI Web of Science Clarivate Analytics USA and Crossref Indexed Journal

\section{Clarivate
Analytics}

NAAS Journal Score 2020 (4.31) SJIF: 2020 (7.728)

A Society of Science and Nature Publication,

Bhopal India 2020. All rights reserved.

Online Contents Available at: http//www.bbrc.in/

Doi: http://dx.doi.org/10.21786/bbrc/13.7/54 patient and operative needs. Drug selection has to consider both components of the anesthetic solution. The local anesthetic agent must have a high intrinsic activity and a low systemic toxicity (Singh, 2012).

Various local anaesthesia injection techniques include infiltration, nerve block, intraosseous, intra pulpal, intra septal, periodontal ligament injection (Reed et al., 2012). The most common method of inducing anesthesia for maxilla is infiltration or supra-periosteal injection technique. In this method, the needle is penetrated in deep vestibular mucosa above the apex of the tooth. Inferior alveolar (I.A) nerve block is the common technique of anesthetizing the mandible. The technique of nerve block anaesthetic injection for adults and children is almost similar. The only difference is that the injection must be a little lower, and more posteriorly for children because the mandibular foramen is lower to the occlusal surface of deciduous teeth (Pinkham and Casamassimo, 1999).

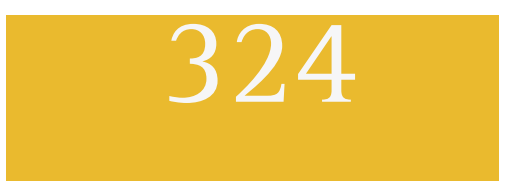


One of the most common complaints following I.A nerve block is soft-tissue injury due to biting lips, tongue, and buccal mucosa. Therefore, the necessity of an alternative method is felt (Sharaf, 1997). Block injection for hemophilic patients who have not received recombinant factors may lead to cervical hematoma or even death (Kumar et al., 2007). However, both methods are characterized by a long-lasting action, mostly longer than needed, and possible significant complications like nerve injuries. Moreover, as patients are getting older, cardiovascular and medicinal issues have to be taken into account when dental anesthesia is performed. A less known and used technique is represented by the intraligamentary anesthesia, which has unique characteristics and advantages (Doris Burtscher, 2019).

In order to reduce these undesirable side effects from other techniques, first attempts were made already at the beginning of the 20th century in order to anesthetize single teeth directly without influencing the nerve structures of the surrounding tissues (Meechan, 1992). In 1920 Chompret published his experiences entitling his work "Anesthésie par injections intraligamenteuses"(Doris Burtscher, 2019) . During the following decades the described technique of intraligamentary anesthesia (ILA) was refined simultaneously to the development of new anaesthetic devices. These instruments enabled the injection of the anesthetic solution in the periodontal ligament against the high periodontal tissue resistance (back-pressure) with only little effort by the dentist himself(Baghlaf et al., 2018). The results of histologic evaluations after the PDL injection was administered indicated minimal damage to the crestal bone, followed by rapid repair and healing(Walton and Garnick, 1982).

Intraligamentary injection was given using short 27- or 30- gauge dental needles for this technique. With the tip of the needle approaching the periodontal sulcus on the mesial or distal aspect of the tooth, the needle should be advanced to the base of the periodontal crevice. With the bevel oriented toward the root surface, the needle is advanced into the PDL between the root surface and the adjacent alveolar bone. A small amount ( 0.2 milliliters) of anesthetic solution should be administered slowly. To ensure that the solution is being forced into the tissue, we must feel resistance. Although syringes differ among manufacturers, the technique usually requires deposition of at least $0.2 \mathrm{~mL}$ for each root of the tooth (Malamed, 2012).

Although occasionally it is used as the primary anesthetic technique (when a single tooth requires anesthesia for a short duration), dentists most often use the PDL technique when mandibular nerve blocks are unsuccessful (Nusstein et al., 2010). The PDL injection provides pulpal anesthesia to the tooth, with only localized soft tissue anesthesia developing. When administered in the mandible, there is no associated extraoral or lingual anesthesia like traditional inferior alveolar nerve block (Saxena et al., 2013). Intraligamentary injections are given in children and mentally handicapped patients. Intraligamentary anesthesia clearly reduces the risk of post-operative bite injuries since it does not cause numbness in the cheeks, tongue or lips (MIB GmbH, n.d.). The application of high pressure is required to deliver the local anaesthesia into the dense oral tissues at the PDL injection site. This has resulted in many patients complaining that the PDL injection was painful (Saxena et al., 2013).

Previously our department has published extensive research on various aspects of prosthetic dentistry (Anbu et al., 2019; Ariga et al., 2018; Ashok and Ganapathy, 2019; Duraisamy et al., 2019; Ganapathy et al., 2017; Gupta et al., 2018; Jain, 2017a, 2017b; Ranganathan et al., 2017; Varghese et al., 2019; World Journal of Dentistry, 2017), this vast research experience has inspired us to research about awareness on intraligamentary injection among dental students.

As intraligamentary injection has various advantages and can be used as an alternative for various other techniques, the present study aimed at assessing the knowledge and awareness of intraligamentary anaesthesia among dental students.

\section{MATERIAL AND METHODS}

The study was done in an online setting among the dental students of the Chennai population. Institutional review board approval was obtained for this survey based analysis. 2 reviewers [Primary investigator \& guide] were involved in this study. The sample size of 151 participants of age group 20-23 years , both males and females were selected by a simple random sampling method. Randomisation [for all variables] was followed to minimise the bias. Pre tested questionnaires where the internal validity was the homogenisation and replication of experiment. Cross verification with existing studies was the external validity of this study. The set of questionnaires which includes gender, questions on awareness were circulated among the participants through an online link. The results were collected and tabulated. Then the results were exported for statistical analysis to SPSS statistical software. Both descriptive ( frequency of the responses) and inferential statistics (Chi - square tests) were done and the results were presented in the forms of graphs.

\section{RESULTS AND DISCUSSION}

According to this survey based study it was noted that the males(52.98\%) have participated in higher numbers compared to females(47.02\%) [Figure 1]. It was noted that $79.47 \%$ of the population participated in the study were aware of the term intraligamentary injection whereas 20.53\% of the population was not aware of the term [ Figure2]. Among the participants, 74.83\% of them had given intraligamentary injection to their patients while $25.17 \%$ had never given intraligamentary injection [Figure 3]. About 68.87\% of participants were aware about the technique used to give intraligamentary injection while $31.13 \%$ were not aware about the technique [Figure 4]. For intraligamentary injection, 27- and 30- gauge needles were used and 64.24\% of 
participants were aware about it but 35.76\% were not aware about it [Figure 5].

Figure 1: Pie chart showing percentage distribution of the population according to gender participated in the study. 52.98\% were males (Blue) whereas $47.02 \%$ were females(Green) participated in the study. $\mathrm{N}=151$. Males have participated in higher numbers in this survey.

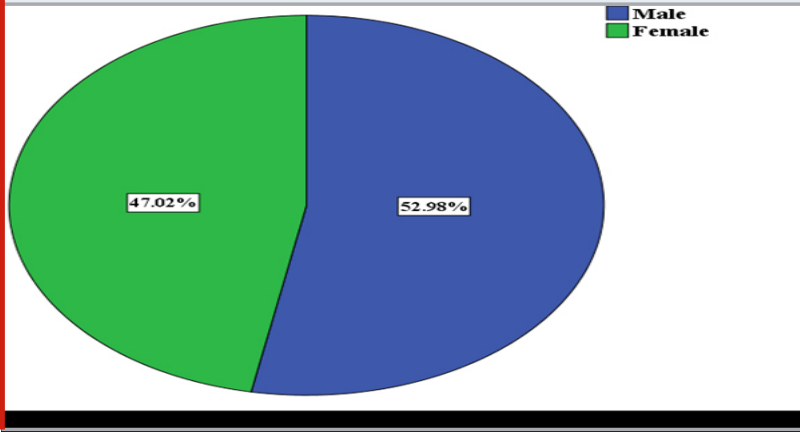

Figure 2: Pie chart showing percentage distribution of the awareness of the term intraligamentary injection among the participants participated in the study. $79.47 \%$ were aware of the term (Blue) whereas $20.53 \%$ were not aware of the term(Green). $N=151$. There is increased awareness of the term intraligamentary injection among the study participants.

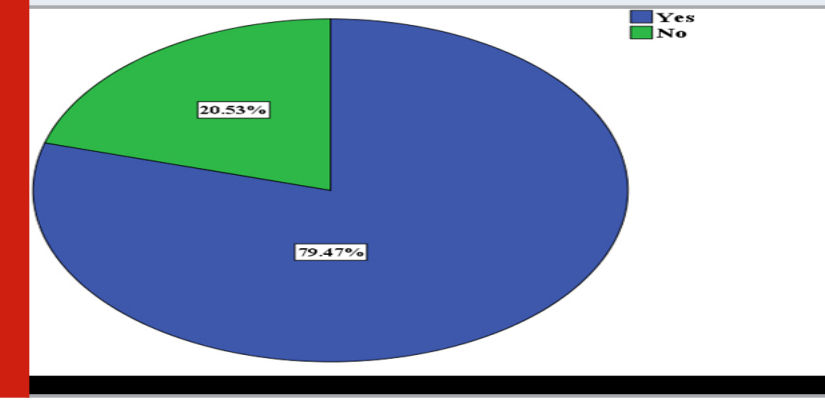

Figure 3: Pie chart showing percentage distribution of the students who had performed intraligamentary injection in patients among the participants. $68.87 \%$ had given intraligamentary injections to patients previously (Blue) and 31.13\% had never given intraligamentary injections to patients (Green). $N=151$. There is an increased number of participants who had given intraligamentary injections to their patients.

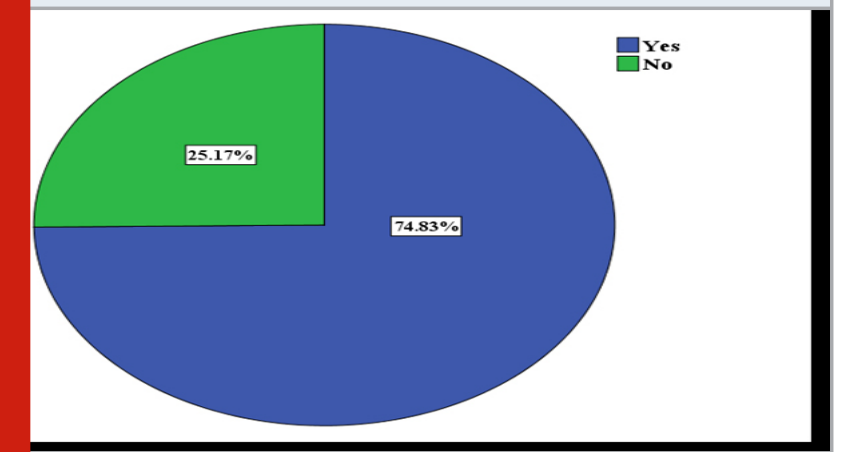

Figure 4: Pie chart showing percentage distribution of the awareness about the technique used to give intraligamentary injection among the participants participated in the study. 64.24\% were aware about the intraligamentary injection technique (Blue) whereas $35.76 \%$ were not aware of the intraligamentary injection technique (Green). N=151. There is increased awareness of the intraligamentary injection technique among the study participants.

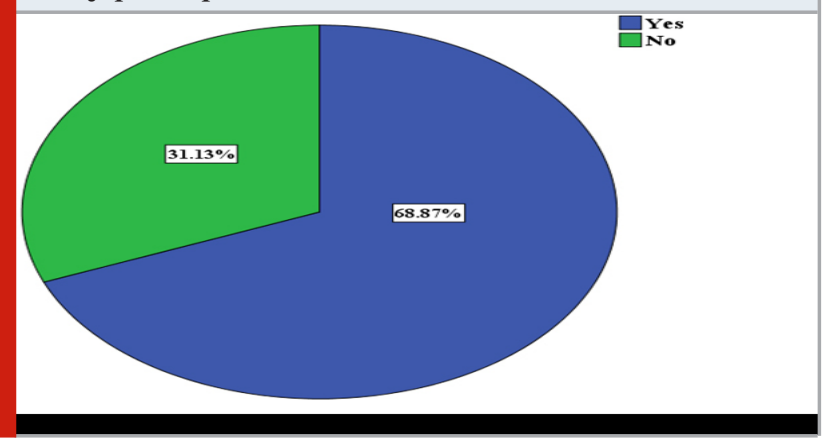

Figure 5: Pie chart showing percentage distribution of the awareness about gauge needle size used to give intraligamentary injection among the participants participated in the study. $64.24 \%$ were aware about the gauge needle used during intraligamentary injection (Blue) whereas 35.76\% were not aware of the gauge needle used in intraligamentary injection technique (Green). $\mathrm{N}=151$. There is increased awareness of the gauge needle no. used in intraligamentary injection technique among the study participants.

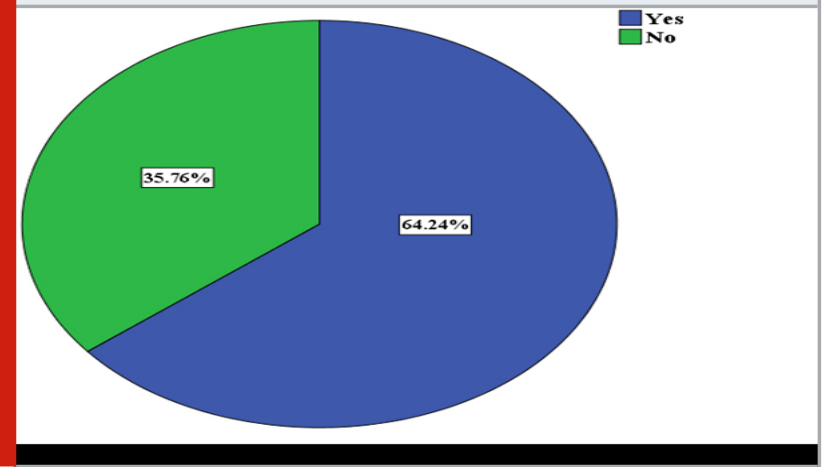

50.99\% of participants' patients complained of pain during intraligamentary injection while $49.01 \%$ of participants' patients could bear the pain [Figure 6]. Among the participants, $24.50 \%$ gave intraligamentary injection into only one surface, $57.62 \%$ gave intraligamentary injection into two surfaces and $17.88 \%$ gave intraligamentary injection into three surfaces [Figure 7]. About 51.66\% of participants were aware about the special apparatus used for intraligamentary injection while $48.34 \%$ of participants were not aware about the special apparatus [Figure 8]. Intraligamentary injection is used as alternative when nerve block fails and $66.23 \%$ were aware about it while $33.77 \%$ were not aware about it [Figure 9]. 
Figure 6: Pie chart showing percentage distribution of the patient's reaction to intraligamentary injection given by students among the participants participated in the study. $50.99 \%$ of patients had pain during the intraligamentary injection (Blue) whereas $49.01 \%$ of patients were able to bear the pain during intraligamentary injection (Green). $\mathrm{N}=151$. It is shown that an increased number of patients had pain during intraligamentary injection.

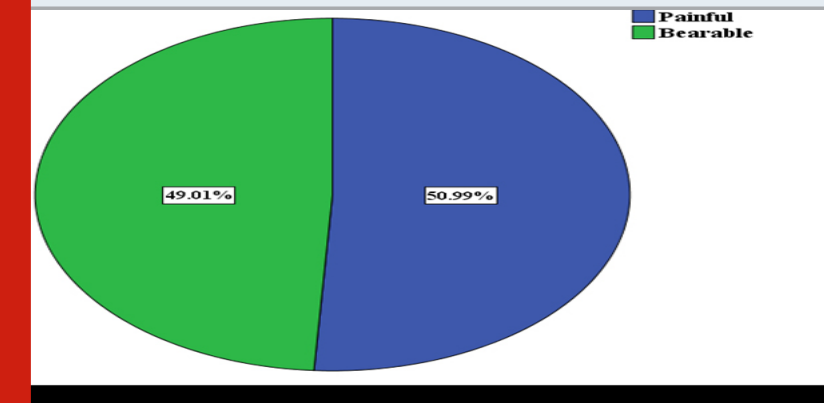

Figure 7: Pie chart showing percentage distribution of the number of surfaces injected during intraligamentary injection by the participants participated in the study. $57.62 \%$ of participants injected into only one surface during the intraligamentary injection (Blue) whereas $24.50 \%$ of participants injected into two surfaces during the intraligamentary injection (Green) and 17.88\% of participants injected into three surfaces during the intraligamentary injection (Brown). $\mathrm{N}=151$. It is shown that an increased number of participants had given intraligamentary injection into one surface.

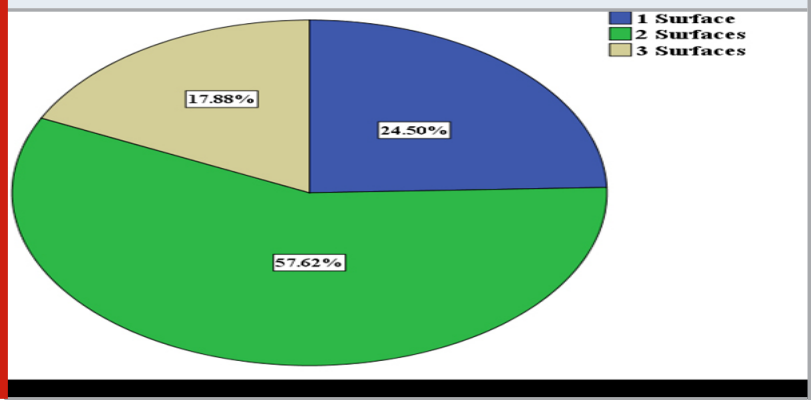

Among the participants, 68.87\% were aware that high pressure should be given during intraligamentary injection while $31.13 \%$ were not aware about it [Figure 10]. About 25.83\% of participants had given intraligamentary injection for pregnant women, 40.40\% had given it for hemophilic patients and 33.77\% had given intraligamentary injection to immunocompromised patients [Figure 11].

Association of gender and awareness of the term intraligamentary injection was found to be statistically significant with a p value of 0.029 [Figure12]. Association between gender and the participants who had used intraligamentary injection in their practice was found to be not statistically significant $(p=0.423)$ [Figure13]. Association of gender and awareness of the technique used in intraligamentary injection was not statistically significant with a p value of 0.307 [Figure14]. Association of gender and awareness among the participants that intraligamentary injection was used when nerve block fails was not statistically significant with a $\mathrm{p}$ value of 0.084 [Figure15].

Figure 8: Pie chart showing percentage distribution of awareness about special injection apparatus used in intraligamentary injection by the participants participated in the study. $48.34 \%$ of participants are aware about special injection apparatus used in the intraligamentary injection (Blue) whereas 51.66\% of participants are not aware about special injection apparatus used in the intraligamentary injection (Green). $\mathrm{N}=151$. It is shown that an increased number of participants were not aware about the special injection apparatus used in the intraligamentary injection

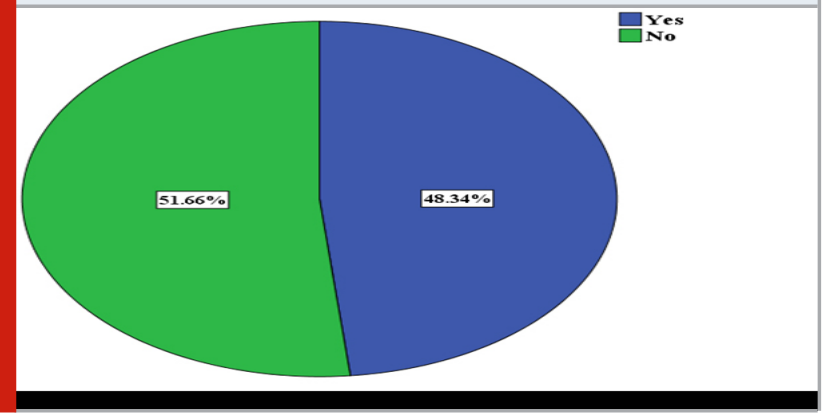

Figure 9: Pie chart showing percentage distribution of participants aware of using intraligamentary injection as alternative during nerve block failure among the participants participated in the study. 66.23\% of participants were aware of using intraligamentary injection as alternative during nerve block failure (Blue) whereas $33.77 \%$ of participants were not aware about using intraligamentary injection as alternative during nerve block failure(Green). $\mathrm{N}=151$. It is shown that an increased number of participants were aware of using intraligamentary injection as alternative during nerve block failure.

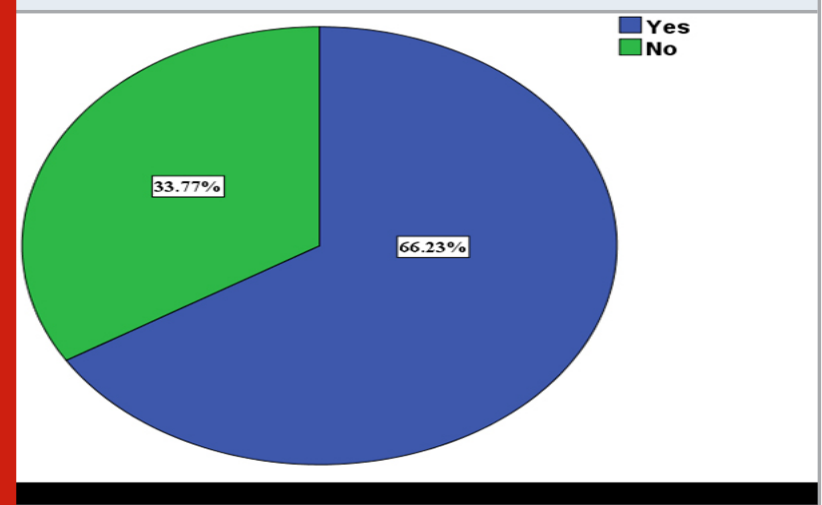

According to the survey, it was found that the participants were more aware about the intraligamentary injection and also males were more aware compared to females. According to Vinitha G et.al, the dental students who were 
aware of periodontal ligament injection technique are $68 \%$ where $32 \%$ of people are not aware of periodontal ligament injection (Vinitha and Student, n.d.).This finding was similar to the present study. Also,.58\% of people use 2 surfaces for giving periodontal ligament injection while 23\% use 3 surfaces for giving periodontal ligament injection where 18\% only use 1surface for giving injection .This finding was in agreement with the present study. According to Vinitha G et.al, 43\% dental students use periodontal ligament technique for extraction when routine nerve block fails which was contradictory to the present study since more number of participants use intraligamentary injection as alternative when nerve block fails. And only 25\% of students in the previous study had used this technique for haemophilic patients (Vinitha and Student, n.d.)which was opposing the present study since $40.40 \%$ of dental students in the present study had used intraligamentary injection for hemophilic patients.

Figure 10: Pie chart showing percentage distribution of participants aware about high pressure given during intraligamentary injection among the participants participated in the study. $68.87 \%$ of participants were aware that high pressure should be given during intraligamentary injection (Blue) whereas $31.13 \%$ of participants were aware that high pressure should be given during intraligamentary injection(Green). $\mathrm{N}=151$. It is shown that increased participants were aware that high pressure should be given during intraligamentary injection.

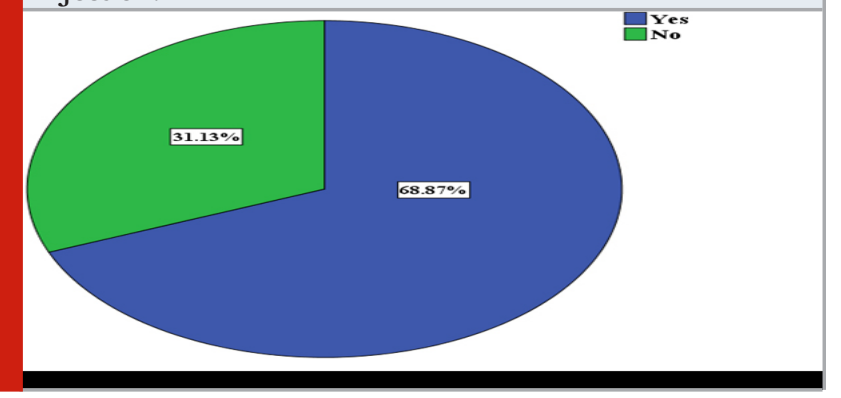

Figure 11: Pie chart showing percentage distribution of type of patients among which intraligamentary injection was used more commonly by the participants participating in the study. $25.83 \%$ of pregnant women were given intraligamentary injection (Blue) whereas $40.40 \%$ of hemophilic patients were given intraligamentary injection (Green) and 33.77\% of immunocompromised patients were given intraligamentary injection (brown). $\mathrm{N}=151$. It is shown that intraligamentary injection was given more commonly among hemophilic patients.

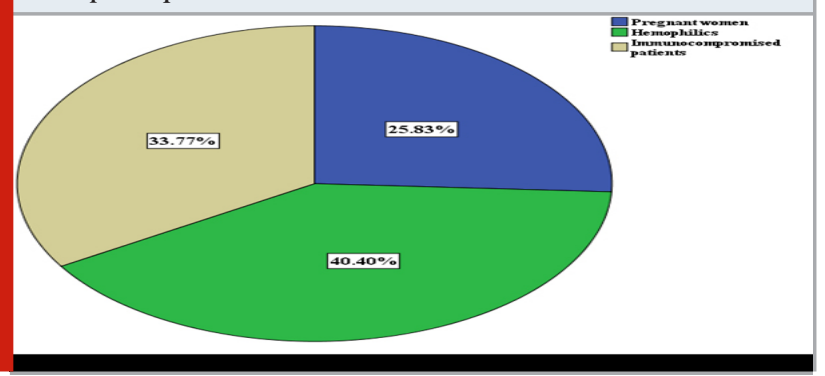

Figure 12: The bar graph represents the association of gender and awareness of the term intraligamentary injection among the participants. The $\mathrm{X}$ - axis represents the gender and the $\mathrm{Y}$ - axis represents the number of participants. Among the total participants, males (45.7\%) were more aware of the term intraligamentary injection compared to females $(33.77 \%)$. This association was statistically significant.(Pearson Chi square value:4.794; $\mathrm{p}=0.029(<0.05)$.

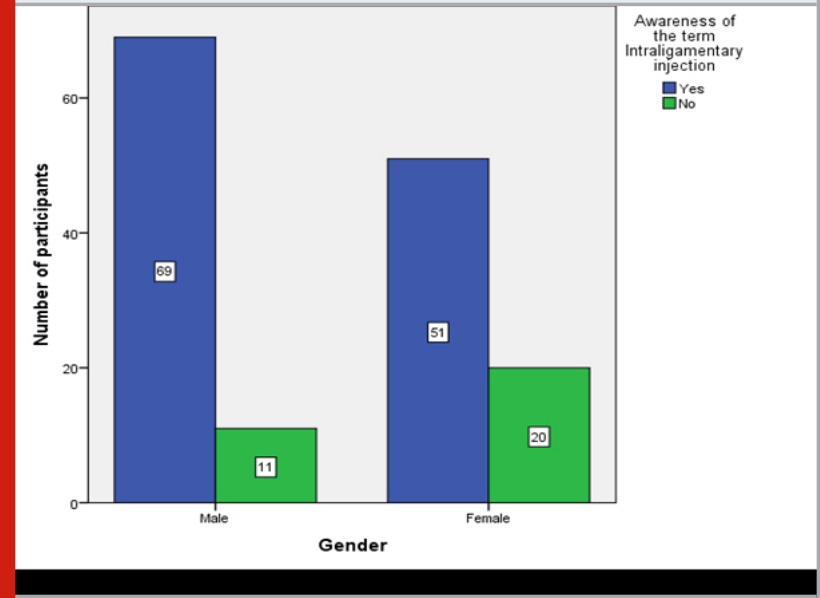

Figure 13: The bar graph represents the association of gender and the number of participants who had given intraligamentary injection among the participants. The $\mathrm{X}$ - axis represents the gender and the $\mathrm{Y}$ - axis represents the number of participants. Among the total participants, males $(41.06 \%)$ had given more intraligamentary injections to patients compared to females (33.77\%). This association was not statistically significant.(Pearson Chi square value:0.642; $\mathrm{p}=0.423(>0.05)$.

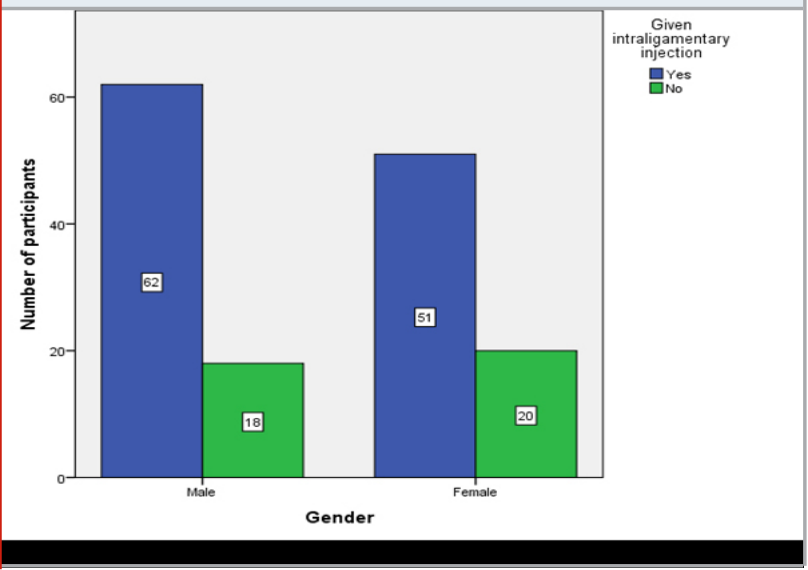

When the inferior alveolar nerve block was inadequate to provide profound pulpal anesthesia in mandibular posterior teeth of patients with irreversible pulpitis, the intraligamentary injection administered with a computercontrolled local anesthetic delivery system was successful approximately 56\% of the times. (Nusstein et al., 2005). The intraligamentary injection (periodontal ligament injection) allows placement of a local anesthetic solution 
into the cancellous bone adjacent to the tooth to be anesthetized (Walton and Abbott, 1981). The success of supplemental intraligamentary injections in achieving pulpal anesthesia in endodontic therapy has been reported to be 50 to $96 \%$. Traditionally, intraligamentary injections have been administered with a conventional syringe or high-pressure syringe (Nusstein et al., 2005). Milestone Scientific has recently developed a specialized Wand called the Computer-Controlled Drug Delivery System (CCDDS). The new system incorporates all of the previous Wand technology with additional advances. The improved unit includes a visual display showing the precise volume of drug delivered and the pressures developed during drug delivery. A critical factor in the success of intraligamentary injection is achieving strong back pressure (Walton and Abbott, 1981). This new system will allow direct monitoring of the pressures achieved during intraligamentary injection.

Figure 14: The bar graph represents the association of gender and awareness about the technique used to give intraligamentary injection among the participants. The $\mathrm{X}$ - axis represents the gender and the $\mathrm{Y}$ - axis represents the number of participants. Among the total participants, males (38.41\%) were more aware of the technique used to give intraligamentary injection compared to females (30.46\%). This association was not statistically significant. (Pearson Chi square value:1.043; $\mathrm{p}=0.307(>0.05)$.

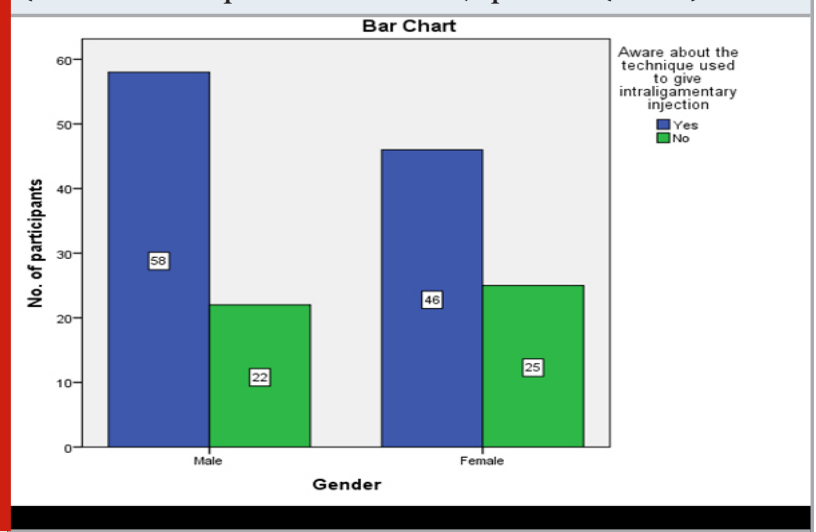

Lalabonova et al., in their prospective study on 220 general dental practitioners to evaluate the use of intraligamentary injection showed that 75.91\% Bulgarian dental practitioners use intraligamentary injection in almost all treatments in which $32.94 \%$ showed adequate anesthesia (Lalabonova et al., n.d.). Using intraligamentary anesthesia bacteremia was observed in 50-97\% (Roberts et al., 1998). With intraligamentary injection, positive aspiration was observed in the form of a thin stream with a frequency of 34/36/94.4\% (Petrikas et al., 2019). medicine. Thus understanding the techniques, indications, contraindication, post- operative complications and success rate of intraligamentary injection will help clinicians increase their working efficacy.
Figure 15: The bar graph represents the association of gender and awareness among the participants that intraligamentary injection is used as an alternative when the nerve block fails. The $\mathrm{X}$ - axis represents the gender and the $\mathrm{Y}$ - axis represents the number of participants. Among the total participants, males (38.41\%) were more aware that intraligamentary injection is used as an alternative when the nerve block fails compared to females (27.81\%). This association was not statistically significant. (Pearson Chi square value:2.995; $\mathrm{p}=\mathbf{0 . 0 8 4}(>0.05)$.

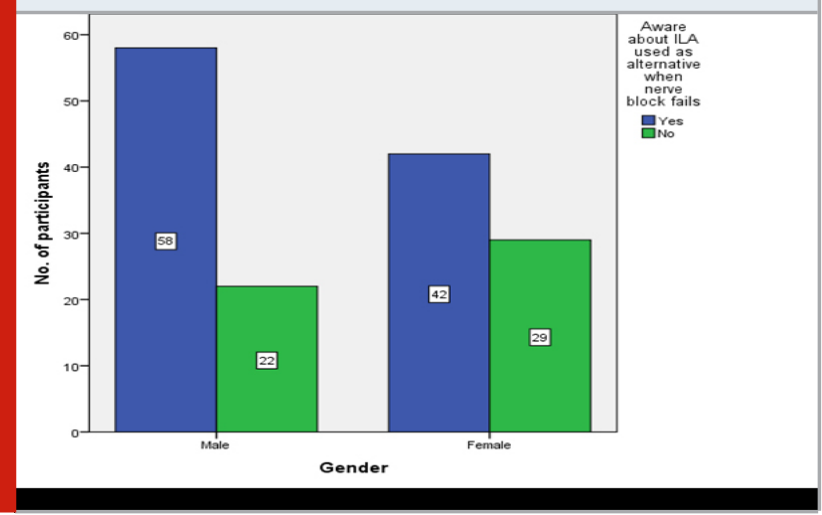

\section{CONCLUSION}

Within the limits of the study, dental students were more aware about the intraligamentary injection. Males were more aware of the intraligamentary injection compared to females.More awareness programs should be initiated to further improve the quality of treatment rendered to the patients.

\section{ACKNOWLEDGEMENTS}

We would like to thank the administration of Saveetha University, Chennai for granting us the clearance to conduct this study and for finding this research.

Author's contribution: A.Ashwatha Pratha contributed to study conception and design, data collection, analysis and interpretation and drafted the work. Dr.Dhanraj Ganapathy contributed to data interpretation, study design and data collection. All authors critically reviewed the manuscript and approved the final version.

The authors declare no conflict of interest.

\section{REFERENCES}

Anbu RT, Suresh V, Gounder R, et al. (2019) Comparison of the Efficacy of Three Different Bone Regeneration Materials: An Animal Study. European journal of dentistry 13(1): 22-28.

Ariga P, Nallaswamy D, Jain AR, et al. (2018) Determination of Correlation of Width of Maxillary Anterior Teeth using Extraoral and Intraoral Factors in Indian Population: A Systematic Review. World Journal of Dentistry 9(1): 68-75.

Ashok V and Ganapathy D (2019) A geometrical method 
to classify face forms. Journal of oral biology and craniofacial research 9(3): 232-235.

Baghlaf K, Elashiry E and Alamoudi N (2018) Computerized intraligamental anesthesia in children: A review of clinical considerations. Journal of dental anesthesia and pain medicine 18(4): 197-204.

Doris Burtscher DDT (2019) Intraligamentary anesthesia - a brief review of an underestimated anesthetic technique. Oral Health Care 4. Available at: https:// www.oatext.com/intraligamentary-anesthesia-a-briefreview-of-an-underestimated-anesthetic-technique.php (accessed 1 July 2020).

Duraisamy R, Krishnan CS, Ramasubramanian H, et al. (2019) Compatibility of Nonoriginal Abutments With Implants: Evaluation of Microgap at the ImplantAbutment Interface, With Original and Nonoriginal Abutments. Implant dentistry 28(3): 289-295.

Ganapathy DM, Kannan A and Venugopalan S (2017) Effect of Coated Surfaces influencing Screw Loosening in Implants: A Systematic Review and Meta-analysis. World Journal of Dentistry 8(6): 496-502.

Gupta P, Ariga P and Deogade SC (2018) Effect of Monopoly-coating Agent on the Surface Roughness of a Tissue Conditioner Subjected to Cleansing and Disinfection: A Contact Profilometric Study. Contemporary clinical dentistry 9(Suppl 1): S122S126.

Jain AR (2017a) Clinical and Functional Outcomes of Implant Prostheses in Fibula Free Flaps. World Journal of Dentistry 8(3): 171-176.

Jain AR (2017b) Prevalence of Partial Edentulousness and Treatment needs in Rural Population of South India. World Journal of Dentistry 8(3): 213-217.

Kumar JN, Naveen Kumar J, Anil Kumar R, et al. (2007) Specialty dentistry for the hemophiliac: Is there a protocol in place? Indian Journal of Dental Research. DOI: $10.4103 / 0970-9290.32419$.

Lalabonova H, Kirova D and Dobreva D (n.d.) INTRALIGAMENTARY ANESTHESIA IN GENERAL DENTAL PRACTICE. Available at:

https://www.journal-imab-bg.org/statii-05/22-24_br205.pdf.

Malamed SF (2012) Handbook of Local Anesthesia, 6/e. Elsevier India.

Meechan JG (1992) Intraligamentary anaesthesia. Journal of dentistry 20(6): 325-332.

MIB GmbH (n.d.) Local anesthesia techniques. Available at: http://www.med-college.de/en/wiki/ artikel.php?id=196 (accessed 1 July 2020).

Nusstein J, Claffey E, Reader A, et al. (2005) Anesthetic effectiveness of the supplemental intraligamentary injection, administered with a computer-controlled local anesthetic delivery system, in patients with irreversible pulpitis. Journal of endodontia 31(5): 354-358.

Nusstein JM, Reader A and Drum M (2010) Local Anesthesia Strategies for the Patient With a 'Hot'
Tooth. Dental Clinics of North America. DOI: 10.1016/j. cden.2009.12.003.

Petrikas AZ, Medvedev DV, Yakupova LA, et al. (2019) Classification of the Methods of Local Anesthesia and Special Features of Vascular-Diffuse Injection. International Journal of Oral and Dental Health 5(2). DOI: $10.23937 / 2469-5734 / 1510086$.

Pinkham JR and Casamassimo PS (1999) Pediatric Dentistry: Infancy Through Adolescence. W.B. Saunders.

Ranganathan H, Ganapathy DM and Jain AR (2017) Cervical and Incisal Marginal Discrepancy in Ceramic Laminate Veneering Materials: A SEM Analysis. Contemporary clinical dentistry 8(2): 272-278.

Reed KL, Malamed SF and Fonner AM (2012) Local anesthesia part 2: technical considerations. Anesthesia progress 59(3): 127-36; quiz 137.

Roberts GJ, Simmons NB, Longhurst P, et al. (1998) Bacteraemia following local anaesthetic injections in children. British dental journal 185(6): 295-298.

Saxena P, Gupta SK, Newaskar V, et al. (2013) Advances in dental local anesthesia techniques and devices: An update. National journal of maxillofacial surgery 4(1): 19-24.

Sharaf AA (1997) Evaluation of mandibular infiltration versus block anesthesia in pediatric dentistry. ASDC journal of dentistry for children 64(4): 276-281.

Singh P (2012) An emphasis on the wide usage and important role of local anesthesia in dentistry: A strategic review. Dental research journal 9(2): 127132.

Varghese SS, Ramesh A and Veeraiyan DN (2019) Blended Module-Based Teaching in Biostatistics and Research Methodology: A Retrospective Study with Postgraduate Dental Students. Journal of dental education 83(4): 445-450.

Vinitha G and Student BDS (n.d.) A Survey on Knowledge of Dental Students about Periodontal Ligament Injection. Available at:

https://www.jpsr.pharmainfo.in/Documents/Volumes/ vol7Issue08/jpsr07081531.pdf.

Walton RE and Abbott BJ (1981) Periodontal ligament injection: a clinical evaluation. Journal of the American Dental Association 103(4). jada.ada.org: 571-575.

Walton RE and Garnick JJ (1982) The periodontal ligament injection: histologic effects on the periodontium in monkeys. Journal of Endodontics. DOI: 10.1016/ s0099-2399(82)80312-9.

World Journal of Dentistry (2017) Evaluation of Corrosive Behavior of Four Nickel-chromium Alloys in Artificial Saliva by Cyclic Polarization Test:An in vitro Study. 8(6): 477-482.

Yamashiro M and Furuya H (2006) Anesthetic Management of a Patient With Sturge-Weber Syndrome Undergoing Oral Surgery. Anesthesia Progress. DOI: 10.2344/0003-3006(2006)53[17:amoapw]2.0.co;2. 